\title{
Evaluation and Comparison of the Outcomes of Endoscopic Dacryocystorhinostomy with and without Silicone Stent
}

https://doi.org/10.47210/bjohns.2020.v28i3.310

Bipin Kishore Prasad, ${ }^{1}$ Krishna Kamal Ghosh ${ }^{2}$

Introduction

ABSTRACT

Endoscopic dacryocystorhinostomy aims to establish a patent nasolacrimal fistula. Use of silicone stent is a preferred modification to achieve long term patency of neo-ostium, though it has been blamed for granulations, synechia and punctal erosion. Present study was done to evaluate and compare the outcomes of Endoscopic dacryocystorhinostomy with and without stent.

Materials and Methods

40 patients of with chronic dacryocystitis and nasolacrimal duct blockage were selected for the study. Nasal endoscopy was done for suitability of surgical access and to detect any nasal pathology. Sac syringing was done to assess the site of blockage and Dacryoscintigraphy to confirm it. 20 patients in Group A underwent Endoscopic dacryocystorhinostomy without stent and remaining 20 in Group B with silicone stent. Success rates were determined by subjective relief from epiphora and by endoscopic visualization of rhinostomy opening, granulation tissues/ synechiae at rhinostomy site and by result of sac syringing.

\section{$\underline{\text { Results }}$}

In Group A, complete relief was obtained in $75 \%$ patients, significant relief in $10 \%$ and no relief in $15 \%$ patients thus recording overall success rate of $85 \%$; whereas in Group B complete relief of symptom was obtained in $70 \%$ patients, significant relief in $10 \%$ and no symptom relief in $20 \%$ patients thus recording the overall success rate of $80 \%$. Cases in Group B were also found to have persistent epiphora (17.5\%), stenosis of ostium (25\%), granulation (35\%) and synechia (37.5\%).

Conclusion

Stenting does not significantly improve the success of Endoscopic dacryocystorhinostomy but is associated with more complications.

$\underline{\text { Kevwords }}$

Endoscopic; Dacryocystorhinostomy; Stenosis; Synechia; Granulation; Epiphora; Chronic dacryocystitis; Silicon stent; Nasolacrimal duct

$\mathrm{D}$ acryocystorhinostomy (DCR) is the surgery performed to direct the lacrimal flow into nasal cavity through an artificial opening made at the level of lacrimal sac. It is indicated in cases of symptomatic distal obstruction of nasolacrimal duct (NLD) which is not relieved by simple probing and syringing. Endoscopic DCR (Endo DCR) is the preferred approach over external DCR due to its two major advantages, namely (a) preservation of pumping action of orbicularis oculi muscle and (b) correction of associated nasal pathology.
The aim of DCR surgery is not only to establish a nasolacrimal fistula but also to keep it patent. Use of local topical application of Mitomycin C and insertion of

1 - Department of ENT and HNS, Command Hospital (EC) Alipore Road, Kolkata

2 - Department of ENT, Basirhat Superspecialty Hospital,

Badartala, Itinda Road Basirhat

Corresponding author:

Dr Bipin Kishore Prasad

email: bkp1405@gmail.com 
silicone stent are two commonly preferred modifications in this surgery aiming at long term patency of neo-ostium. Though silicone stent has been reported to improve the surgical outcome of Endo DCR, some studies indicate that the stent itself is a reason of surgical failure due to granulation tissue formation, punctal erosion and slitting of canaliculi. A study was hence conducted to evaluate and compare the outcomes of Endo DCR with and without silicone stent.

\section{Materials and Methods}

This Randomized Controlled Clinical Trial was conducted in a tertiary care Armed Forces hospital over a period of two years in a sample size of 40 subjects without any age or sex bias. Patients attending Eye and ENT OPDs with chronic dacryocystitis and NLD blockage were included in the study. Patients of canalicular blockage, fibrosed punctum and revision cases were excluded from the study. Institutional Ethical Clearance was obtained. Consent from the patients was obtained to participate in the study.

The lids, puncta and medial canthal region were examined for any abnormality. Nasal endoscopy was done for suitability of surgical access and to detect any nasal pathology. Sac syringing was done using saline to assess the site of blockage in lacrimal flow. Dacryoscintigraphy (DCT) was done with Technetium (T99M) to confirm the blockade site. The radioactive tracer was prepared by mixing a diluted mixture of T99M and saline with tin sulphar colloid. Proper dosimetry was done with a specific dosimeter to make it ready for use. 2 drops of the mixture were instilled in both eyes, image was captured in gamma camera and Scintigraph was obtained.

20 patients, randomized by odd-even method of serial numbers, were placed in Group A to undergo Endo DCR without silicone stent and equal number of patients were placed in Group B to undergo Endo DCR with silicone stent which was passed through the lower and upper punctum to come out of the window created in the lacrimal sac wall. Endo DCRs were done under general anesthesia. After endoscopic confirmation of the sac, itsmedial wall was incised vertically by sickle knife and removed by quick bites using Kerrison's punch forceps. Nasal cavity was cleared of all secretions and blood. Lacrimal syringing was done with dilute methylene blue and free flow of fluid was observed endoscopically. 20 patients (Group A) did not undergo stenting; whereas another 20 patients (Group B) underwent stenting.Oral antibiotic (Amoxyclav), analgesics, antibiotic eye drops (ciprofloxacin), and normal saline nasal drop were given to every patient post-operatively for 7 days. Saline nasal douching was started after 7 days and continued for 4 weeks at a dosage of $20 \mathrm{ml} 4$ times a day. Gentle digital massaging of sac region was advised for one month. Silicone stent was removed after 3 months.

The cases were followed up at the end of 1 st week, 2nd week, 1 month and then monthly for 6 months. Follow up examination was done under endoscope by the same surgeon and included syringing. Success rate was determined by subjective as well as objective assessment. Patients were asked to grade the degree of relief from epiphora subjectively using a 3 point scale comprising of (i) completely symptom free (ii) significantly improved (iii) not improved. First two responses were considered as success.

Objective assessment was done using endoscope to visualize the rhinostomy opening, to check for granulation tissues or synechiae and to confirm the appearance or absence of Methylene blue dye in the nasal cavity on syringing. The patients of the two groups were compared for the success rates using the above subjective and objective assessment criteria. Complications of silicone stent were studied, especially with regard to ecchymosis of medial canthal region, granulation tissues at or adjacent to rhinostomy site and synechia formation between nasal septum, middle turbinate and lateral nasal wall.

The results were studied and compared with existing data. The variations were analyzed as a percentage of the two groups. Student's t test was used to compare mean of the groups. The comparison of outcomes (subjective and objective) between two groups were performed by Chi-square test. The $\mathrm{p}$ values smaller than 0.05 were regarded as significant. 
Table I: Demographic and preoperative statistics of patients

\begin{tabular}{|c|c|c|c|c|}
\hline VARIABLE & $\begin{array}{c}\text { ALL } \\
\text { PATIENTS }\end{array}$ & GROUPA & GROUP B & P VALUE \\
\hline \multicolumn{5}{|l|}{ Age (years) } \\
\hline Range & $37-65$ & $37-62$ & 44-65 & \multirow{2}{*}{0.092} \\
\hline Mean & 52 & 50 & 54 & \\
\hline \multicolumn{5}{|l|}{ Gender } \\
\hline Male & 18 & 10 & 8 & \multirow{2}{*}{0.525} \\
\hline Female & 22 & 10 & 12 & \\
\hline \multicolumn{5}{|l|}{ Laterality of eye } \\
\hline Bilateral & 5 & 3 & 2 & \multirow{3}{*}{0.563} \\
\hline Right & 21 & 10 & 11 & \\
\hline Left & 14 & 7 & 7 & \\
\hline \multicolumn{5}{|l|}{ Additional pathology } \\
\hline Mucocele & 11 & 7 & 4 & 0.288 \\
\hline DNS & 17 & 6 & 11 & 0.11 \\
\hline \multicolumn{5}{|l|}{ Yield from sac syringing } \\
\hline Regurgitation from upper punctum & 32 & 14 & 18 & \multirow{2}{*}{0.114} \\
\hline Regurgitation from both punctum & 8 & 6 & 2 & \\
\hline \multicolumn{5}{|l|}{ Dacryocintigraphy } \\
\hline NLD (bilateral) & 16 & 10 & 6 & \multirow{3}{*}{0.254} \\
\hline NLD (right) & 15 & 7 & 8 & \\
\hline NLD (left) & 9 & 3 & 6 & \\
\hline
\end{tabular}

\section{Results}

40 patients of Chronic Dacryocystitis underwent Endo DCR, 20 without stent (Group A) and 20 (Group B) with silastic stent. Majority of the patients were in the age group of 51-60 years. The comparison of the two groups are statistically not significant $(\mathrm{p}=0.092)$. There were 10 male and 10 female in Group A whereas there were 8 male and 12 female in Group B with an overall sex distribution showing female preponderance of $55 \%$. Majority $(87.5 \%)$ presented with unilateral epiphora. $27.5 \%$ were also found to have mucocele. However, the comparison between two groups for both the clinical features epiphora $(p=0.563)$ and mucocele $(p=0.288)$ was insignificant. There were 11 patients $(55 \%)$ with deviated nasal septum (DNS) in Group A and 6 patients $(30 \%)$ in Group B but only one case in Group B with significant DNS was required to undergo endoscopic septoplasty in the same sitting. (Table I)

Sac syringing was done in all cases as preoperative evaluation. Regurgitation of mucopurulent discharge from upper punctum was seen in 14 patients $(70 \%)$ and in 18 patients (90\%) in Group A and B respectively. Regurgitation of mucopurulent discharge from both puncta was seen in 6 patients $(30 \%)$ and in 2 patients $(10 \%)$ in Group A and B respectively. However, 
Table II: Intraoperative findings

\begin{tabular}{|c|c|c|c|c|}
\hline VARIABLE & $\begin{array}{c}\text { ALL } \\
\text { PATIENTS }\end{array}$ & GROUP A & GROUP B & P VALUE \\
\hline Condition of the sac & & & 14 & 0.465 \\
\hline Thin & 30 & 6 & 4 & \\
\hline Thick \& fibrosed & 10 & & & \multirow{2}{*}{0.525} \\
\hline Yield on incising lacrimal sac & & 8 & 10 & 10 \\
\hline
\end{tabular}

difference between the two group was statistically insignificant $(p=0.114)$. (Table I) Dacryscintigraphy was done in all cases. In Group A, 10 cases $(50 \%)$ showed NLD obstruction on both sides, 3 cases $(15 \%)$ on the left side and 7 cases (35\%) on the right. In Group B, 6 cases $(30 \%)$ showed NLD obstruction on both sides, 6 cases $(30 \%)$ on the left side, 8 cases $(40 \%)$ on the right. The difference of two group was statistically insignificant $(p=0.254)$. (Table I)

During the surgery it was observed that $14(70 \%)$ patients of Group A had a thin lachrymal sac and 6 (30\%) patient had thick fibrosed sac. In this group on incising the sac, there was no discharge yield in $8(40 \%)$ patients but $12(60 \%)$ had mucopurulent discharge. Intra-operatively, $16(80 \%)$ patients of Group B were found to have thin lacrimal sac and $4(20 \%)$ had thick fibrosed sac. In this group on incising the sac, there was no discharge yield in $10(50 \%)$ patients but $10(50 \%)$ had mucopurulent discharge. The comparison of the two groups is statistically not significant. (Table II)

The important complications were persistent epiphora $(17.5 \%)$ and stenosis of the ostium (25\%) suggesting failure of surgery, granulation (35\%) at the bone work site and synechia $(37.5 \%)$ between middle turbinate and lateral wall of nasal cavity. The complications such as Orbital ecchymosis, foreign body (FB) sensation, local pain and extrusion of silicone stent were seen in patients in Group B. (Table III)

The patients were assessed on the parameter of degree of relief from symptoms after DCR, namely complete relief, significant relief and no relief. In Group A complete relief was obtained in 15 patients $(75 \%)$, significant relief in 2 patients $(10 \%)$ and no relief in 2 patients $(10 \%)$ thus recording the overall success rate of $85 \%$; whereas in Group B complete relief of symptom was obtained in 14 patients $(70 \%)$, significant relief in 2 patients $(10 \%)$ and no symptom relief in 2 patients $(10 \%)$ thus recording the overall success rate of $80 \%$. (Table IV)

\section{Discussion}

Age and sex of the patients, laterality of symptom, presence or absence of mucocele or DNS are not the factors known to affect the outcome of Endo DCR. Dacryoscintigraphy serves as an important investigation for documentation but it is not mandatory. It does not improve the successful outcome of procedure. Patency of lacrimal system can be determined by sac syringing which by itself is a reliable method and correlates well with successful outcome of endoscopic procedure.

Condition of lacrimal sac is known to affect the result of DCR. In our study, out of $10(25 \%)$ cases of thick fibrosed sacs, 2 amongst 6 in Group A and 1 amongst 4 in Group B, were relieved completely from epiphora recording a success rate of $30 \%$ only. The finding is similar to the study of Krishnan et al. which reported the success rate of only $29 \%$ with fibrosed sacs. ${ }^{1}$

The complications of Endo DCR are similar to any other nasal endoscopic surgery and include bleeding, wound infection, granulation, synechiae, damage to the orbital contents and surgical failures. Synechia is a significant complication in our study, which has also been reported by Metson, to strongly influence the 
Table III: Postoperative complications

\begin{tabular}{|c|c|c|c|c|}
\hline VARIABLE & GROUPA & GROUP B & $\begin{array}{c}\text { ALL } \\
\text { PATIENTS }\end{array}$ & P VALUE \\
\hline \multicolumn{5}{|l|}{ Complications } \\
\hline Epiphora & $3(15 \%)$ & $4(20 \%)$ & $7(17.5 \%)$ & 0.677 \\
\hline Regurgitation on post-op syringing & $4(20 \%)$ & $3(15 \%)$ & $7(17.5 \%)$ & 0.677 \\
\hline Granulation & $4(20 \%)$ & $10(50 \%)$ & $14(35 \%)$ & $\begin{array}{c}0.047 \\
\text { (significant) }\end{array}$ \\
\hline Synechia & $4(20 \%)$ & $11(55 \%)$ & $15(37.5 \%)$ & $\begin{array}{c}0.022 \\
\text { (significant) }\end{array}$ \\
\hline Punctal injury & $1(5 \%)$ & $\mathbf{0}$ & $1(2.5 \%)$ & 0.311 \\
\hline Non-visualization of ostium & $2(10 \%)$ & $8(40 \%)$ & $10(25 \%)$ & $\begin{array}{c}0.028 \\
\text { (significant) }\end{array}$ \\
\hline Orbital ecchymosis & $\mathbf{0}$ & $2(10 \%)$ & $2(5 \%)$ & \\
\hline FB sensation & $\mathbf{0}$ & $8(40 \%)$ & $8(20 \%)$ & \\
\hline Pain in operated site & $\mathbf{0}$ & $16(80 \%)$ & $16(40 \%)$ & \\
\hline Extrusion of stent & $\mathbf{0}$ & $1(5 \%)$ & $1(2.5 \%)$ & \\
\hline Epistaxis & $\mathbf{0}$ & $1(5 \%)$ & $1(2.5 \%)$ & \\
\hline
\end{tabular}

surgical outcome if it occurs between rhinostomy site and intranasal structures. ${ }^{2}$

Though Endo DCR with stent was thought to be effective in the prevention of granulations at or/and adjacent to rhinostomy site, which was found in $50 \%$ cases in Group B in our study, was also reported by Unlu et al to be at $42.9 \%$ in Endo DCR with silicone stents and it adversely affected the outcome. ${ }^{3}$

Surgical success or failure can be judged by (a) endoscopic visualization of the rhinostomy opening and (b) regurgitation in sac syringing. The aim of surgery is to provide relief to the patient from epiphora. Patients can be categorized as (i) completely relieved from epiphora, (ii) significantly improved and (iii) no improvement; as done in the present study or as (i) complete cure, (ii) partial cure and (iii) no improvement depending upon symptomatic relief. ${ }^{4}$

Bony window of adequate size is a key factor in achieving good results in Endo DCR which can be achieved by using $2 \mathrm{~mm}$ Kerrison's punch alone ${ }^{5}$ or supplemented with burr or septal chisel. ${ }^{6}$ The surgeon has to make his own judgment about the adequacy of the size of bone window. Increasing the size not only increases the duration of the operation but also patient's

Table IV: Surgical success

\begin{tabular}{|c|c|c|c|c|}
\hline RELIEF OF SYMPTOM & GROUP A & GROUP B & ALL & \multirow{2}{*}{ P VALUE } \\
\hline No relief from symptom & 3 & 4 & 7 & \\
\hline Significant relief & 2 & 2 & 4 & 0.915 \\
\hline Complete relief & 15 & 14 & 29 & \\
\hline Success rate & $17(85 \%)$ & $16(80 \%)$ & $33(82.5 \%)$ & 0.677 \\
\hline
\end{tabular}


discomfort.

On the other hand, smaller size of rhinostomy despite silicone stenting lowers the success rate. A study by Kong et al reported that the average onset of ostium closer after the primary operation was 6 to 26 weeks (mean 12.7 weeks). ${ }^{7}$ A total of 7 patients (17.5\%), 3 without stent and 4 with stent, continued to have epiphora post-operatively in our study. It was comparable to the finding of persistent epiphora in post operative period in $16 \%$ cases by Shoaib et al. out of 31 patient studied in 2012. ${ }^{8}$ Narrowing of the bony neo-ostium along with formation of granulations were the possible causes of the recurrence of the epiphora. Inadequacy to create a sufficiently large stoma leading to post operative contracture of the size can be an important factor.

During sac syringing, we observed and checked for free flow on the 7th and 14th day post operatively and then on monthly basis for 6 month. Regurgitation of fluid or partial regurgitation from same or upper punctum was observed in failure cases during 4 th or 5 th follow up (between 3 to 4 month post operatively) in our study. Similar analysis of case series by Boush et al showed that the majority of surgical failures occurred within 4 months of Endo DCR. ${ }^{9}$

Other complications seen in our study were orbital echymosis, foreign body sensation in operated site, pain and extrusion of stent. Orbital echymosis was also found in 4 cases by a similar study upon 46 patients by Saratziotis et al (2009). ${ }^{10}$ Extrusion of stent and difficulties of removing stent because of its submucosal submersion in one case each was also observed by Kakkar et al.(2009) among 20 patients. ${ }^{11}$ Other causes of failed dacryocystorhinostomy, such as obliterated sac and impaired canalicular function were not seen in our study. ${ }^{12}$

Silicone stents are used to keep the canalicular walls and or lacrimal sac nasal mucosal flap separated so as to maintain the patency of the neo-ostium. Though it is a debatable issue, it is popular among ENT surgeons all around the world. Singh reported success rate of $92.6 \%$ ofEndo DCR without stent with no major complication. 5 On the other hand, Welhalm and Huges (1984) have implicated stents for increased incidence of complications and post-operative Failure. ${ }^{13}$ There are others like Massaro and Gonnering (1990), who believe that stenting offers benefits that outweigh any possible adverse effects. ${ }^{14}$ The use or silicone stents in complicated DCR surgery is a well established means of maintaining fistula patency where an otherwise narrow or traumatized passage will narrow further during healing as opined by Patrinely and Anderson (1986). ${ }^{15}$

We achieved $80 \%$ success rate with intra operative placement of stent and $85 \%$ without stenting thus recording an overall success rate at $82.5 \%$ in our study. This result is comparable to many other workers. Kakkar and Chugh reported a success of $85 \%$ patients with stent and $90 \%$ patients without stent. ${ }^{10}$ Sprekelson reported success with Endo DCR with stent in $85 \%$ patients. ${ }^{16} \mathrm{Jin}$ reported primary success rate of $83 \%$ with Endo DCR with stent but also the obstruction of neo-ostium by granulation tissue in $17.4 \%$ cases. ${ }^{17}$

\section{Conclusion}

The present study shows that there is no statistically significant difference in the rates of patency following Endo DCR with or without use of Silicone stents. Patient's compliance and comfort is much better without placement of stent. The use of stents is associated with complications like formation of granulation, synechia, loss or submucosal submersion of stents, extrusion of stent, foreign body sensation and pain in operated site.

\section{References}

1. Krishnan G, Prepageran N, Muthu K. Endoscopic endonasal Dacryocystorhinostomy. Med J Malaysia 2002; 57(4): 404-7

2. Metson R. Endoscopic surgery for lacrimal obstruction. Otolaryngol Head Neck Surg. 1991; 104: 473-9

3. Unlu HH, Toprak B, Aslan A, Guler C. Comparison of surgical outcomes in primary endoscopic dacryocystorhinostomy with and without silicone intubation. Ann Otol Rhinol Laryngol. 2002; 111(8): 704-9

4. Shrestha S, Kafle PK, Pokhrel S, Maharajan M, Toran KC. Success rate of endoscopic Dacryocystorhinostomy at KMC, Kathmandu University Medical Journal 2010; 8(2):195-8

5. Mangal S, Vimal J, Gupta SC, Singh SP. Intranasal endoscopic DCR (END-DCR) in cases of dacryocystitis. Indian Journal of Otolaryngology and Head and Neck Surgery 2004; 56: 177-83 
6. Weidenbecher M, Hosemann W, Buhr W. Endoscopic endonasal dacryocystorhinostomy: results in 56 patients. Ann Otol Rhinol Laryngol. 1994; 103:363-7

7. Kong YT, Kim TI, Byung WK. A report of 131 cases of endoscopic laser lacrimal surgery. Ophthalmology 1994; 101: 793-800

8. Shoaib KK, Ahmed S, Manzoor M, Ahmed S, Syed IA, Haq $\mathrm{N}$ ul. Problems/ Complications, Success Rate - Endoscopic Dacryocystorhinostomy Pak J Ophth. 2012; 28(1): 17-21

9. Boush GA et al. Results of endonasal laser-assisted dacryocystorhinostomy. Ophthalmology 1994; 101(5):955-9

10. Saratziotis A, Emenuelli E, Goueris H, Babighian G. Endoscopic Dacryocystorhinostomy for acquired nasolacrimal duct obstruction: creating a window with a drive without use of mucosal flap. Acta Otolaryngol. 2009; 129(9): 992-5

11. Kakkar V, Chugh J P, Sachdeva S et al. Dacryocystorhinostomy with and without silicone stent: A comparative study. The Internet Journal of Otorhinolaryngology 2009; 9: 1

12. Jokinen K, Kajra J. Endonasal Dacryocystorhinostomy. Archives of olaryngology 1974; 100: 41-4

13. Welham R A., Hughes S.M. Lacrimal surgery in children. American Journal of Ophthalmology 985; 99: 27-34

14. Massaro BM, Gonnering RS, Harris GJ. Endonasal laser Dacryocystorhinostomy. Arch Ophth. 1990; 108:1172-6

15. Patrinely JR, Anderson RL. A review of lacrimal surgery. Ophthalmic reconstructive surgery 1986; 2: 97-102

16. Sprekelson MB. Endoscopic dacryocystorhinostomy - surgical techniques and results. Laryngoscope 1996; 106: 187-9

17. Jin HR, Yeon JY, Choi MY. Endoscopic Dacryocystorhinostomy: Creation of a Large Marsupialized Lacrimal Sac J Korean Med Sci. 2006; 21(4): 719-23. 